\title{
Effect of Raw and Extruded Propionic Acid-Treated Field Beans on Energy and Crude Protein Digestibility (In-Vitro and In-Vivo), Growth and Carcass Quality in Grow-Finisher Pigs
}

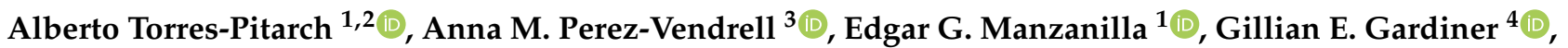 \\ Tomas Ryan ${ }^{1}$, John V. O Doherty ${ }^{2}\left(\mathbb{D}\right.$, David Torrallardona ${ }^{3}{ }^{-1}$ and Peadar G. Lawlor ${ }^{1, *(\mathbb{D}}$ \\ 1 Teagasc, Pig Development Department, Animal and Grassland Research and Innovation Centre, Moorepark, \\ Fermoy, P61 R966 Co. Cork, Ireland; a.torres.pitarch@gmail.com (A.T.-P.); egmanzanilla@gmail.com (E.G.M.); \\ tomas.ryan@teagasc.ie (T.R.) \\ 2 School of Agriculture and Food Science, University College Dublin, Belfield, D04 C7X2 Co. Dublin, Ireland; \\ john.vodoherty@ucd.ie \\ 3 IRTA, Animal Nutrition, Mas Bové, 43120 Constantí, Spain; Anna.perez@irta.cat (A.M.P.-V.); \\ David.torrallardona@irta.cat (D.T.) \\ 4 Department of Science, Waterford Institute of Technology, Co. Waterford, X91 Y074 Waterford, Ireland; \\ ggardiner@wit.ie \\ * Correspondence: peadar.lawlor@teagasc.ie
}

check for

updates

Citation: Torres-Pitarch, A.; Perez-Vendrell, A.M.; Manzanilla, E.G.; Gardiner, G.E.; Ryan, T.; O Doherty, J.V.; Torrallardona, D.; Lawlor, P.G. Effect of Raw and Extruded Propionic Acid-Treated Field Beans on Energy and Crude Protein Digestibility (In-Vitro and In-Vivo), Growth and Carcass Quality in Grow-Finisher Pigs. Animals 2021, 11, 3080. https://doi.org/10.3390/ ani11113080

Academic Editor: Carrie L. Walk

Received: 25 September 2021

Accepted: 21 October 2021

Published: 28 October 2021

Publisher's Note: MDPI stays neutral with regard to jurisdictional claims in published maps and institutional affiliations.

Copyright: (c) 2021 by the authors. Licensee MDPI, Basel, Switzerland. This article is an open access article distributed under the terms and conditions of the Creative Commons Attribution (CC BY) license (https:/ / creativecommons.org/licenses/by/ $4.0 /)$.
Simple Summary: European pig meat production is highly dependent on imported soybean meal (SBM). The area of field beans produced in the EU has increased greatly in recent years. There is renewed interest in field beans as an energy and protein source. Extrusion of raw ingredients can increase their nutritional value. It was hypothesized that propionic acid-treated field beans can be used to replace SBM in finisher diets and that extrusion of field beans will improve their nutritional value. Three experiments were conducted to determine the effect of extrusion of field beans on energy and crude protein digestibility (in-vitro and in-vivo), growth and carcass quality of grow-finisher pigs. Field beans are a good energy and protein source and can be fed at up to $37 \%$ inclusion in pig diets. Extrusion of field beans increased the digestible energy (DE) value, decreased the digestible crude protein $(\mathrm{dCP})$ value of field beans, and had no effect on pig growth.

Abstract: The in-vitro ileal digestibility of dry matter (DM), organic matter (OM), and crude protein $(\mathrm{CP})$ of field beans treated with propionic acid (trFB) and extruded trFB (exFB) was determined in experiment 1 . The $\mathrm{DE}$ and $\mathrm{dCP}$ values of $\operatorname{trFB}$ and exFB were determined using the difference method in experiment 2. The effect of replacing SBM with trFB and exFB in grow-finisher diets on growth, carcass quality, apparent ileal digestibility (AiD), and total tract digestibility (ATTD) of DM, OM, gross energy (GE), and CP were investigated in experiment 3. In exp. 1, in-vitro digestibility of exFB compared to trFB was unchanged for $\mathrm{DM}(p=0.12)$, increased for $\mathrm{OM}(p<0.05)$, and increased for $\mathrm{CP}(p<0.05)$. In exp. 2 , the DE value of $\operatorname{trFB}$ and exFB was 14.38 and $15.75 \mathrm{MJ} / \mathrm{kg}$ respectively; and the $\mathrm{dCP}$ value was $21.35 \%$ and $21.42 \%$ respectively (on DM basis). In exp. 3, ADFI was higher for pigs fed trFB and exFB compared to the control diet (CON; $p<0.05)$, while ADG, FCR and carcass quality parameters of pigs did not differ among treatments $(p>0.05)$.

Keywords: field beans; pigs; extrusion; digestibility

\section{Introduction}

Fluctuations in feed costs and the high dependency of the EU feed sector on the importation of soybean meal (SBM) drive the exploration of alternative protein sources [1,2]. Among others, the use of oilseeds, legume seeds, insect meal, and by-products of biofuel production have been investigated as alternatives to SBM in pig diets [3-6]. Due to policy support for legume crops, the area of field beans (Vicia Faba) produced in the EU has 
increased greatly in recent years; in 2018 the production of field beans in the European Union was 60\% greater than that reported in 2008 (FAO, 2021). On a dry matter basis, field beans contain $23.1 \%( \pm 2.2, \mathrm{SD}), 0.94 \%( \pm 0.2, \mathrm{SD})$, and $13.8 \mathrm{MJ} / \mathrm{kg}( \pm 0.4, \mathrm{SD})$ crude protein $(\mathrm{CP})$, ether extract (EE), and gross energy (GE), respectively [7]. Therefore, there is renewed interest in field beans as an energy and protein source for livestock. Due to the high moisture content at harvesting, raw field beans are commonly treated with propionic acid prior to storage to prevent the proliferation of yeasts and molds. Extrusion which involves thermal and mechanical treatment has been suggested as a good tool to reduce the levels of intrinsic antinutritional factors and increase the nutritional value of legumes $[8,9]$.

In this study it was hypothesized that field beans could be used to replace SBM in diets for grow-finisher pigs. It was also hypothesized that the nutritional value of field beans can be further improved by extrusion. Three experiments were conducted with the objective of determining: (1) The effect of extruding field beans crushed and treated with propionic acid on in-vitro ileal digestibility of dry matter, organic matter, and crude protein; (2) the digestible energy (DE) and digestible crude protein $(\mathrm{dCP})$ value of field beans crushed and treated with propionic acid (trFB) and extruded trFB (exFB); and (3) the effect of replacing SBM with trFB and exFB on growth performance, carcass quality, apparent ileal digestibility (AiD), and total tract digestibility (ATTD) of DM, OM, GE, and $\mathrm{CP}$ in grow-finisher pigs.

\section{Material and Methods}

The care and use of the animals in this study was approved by the Teagasc Animal Ethics Committee (Approval no. TAEC86/2015). The experiment was conducted in accordance with Irish legislation (SI no. 543/2012) and the EU Directive 2010/63/EU for animal experimentation. In this study, the same batch of raw field beans (Vicia Faba, Lynx variety) harvested in Ireland in 2016 was used. The raw field beans were mechanically crushed using a two-roller mill and treated with propionic acid prior to storage. Thereafter, a portion of this batch was extruded $\left(105^{\circ} \mathrm{C}, 5 \times 5 \times 6 \mathrm{~mm}\right.$ die, EXTRU-tech E525, Sabetha, Kansas). The feeder rate was set at $450 \mathrm{~kg} / \mathrm{h}$. The temperature measured at the conditioner was $76 \pm 1.5^{\circ} \mathrm{C}$, at the exit from the dye $98 \pm 3.2^{\circ} \mathrm{C}$ and at the dryer $62 \pm 2.3^{\circ} \mathrm{C}$. The appearance of raw field beans ( $\mathrm{rwFB}), \mathrm{trFB}$, and exFB are presented in Figure 1. The chemical composition of SBM, trFB, and rwFB used in this study is presented in Table 1 $(n=2)$. Laboratory analyses were performed according to the analytical methods described in Section 2.4.

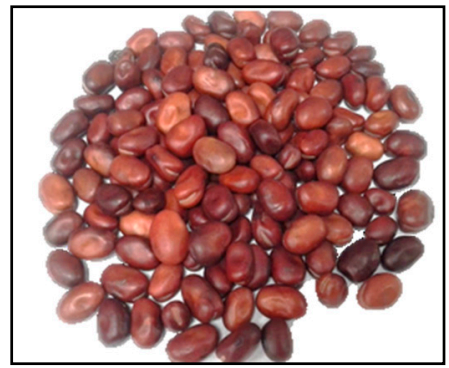

(a)

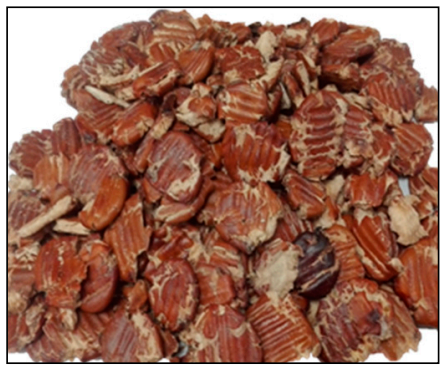

(b)

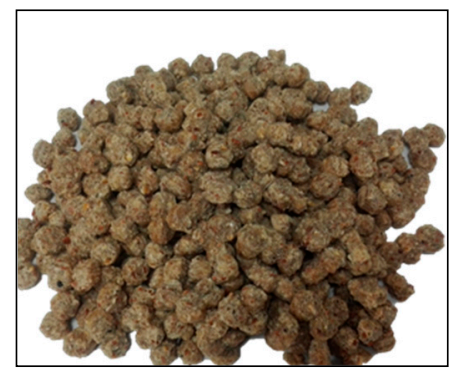

(c)

Figure 1. (a) Raw field beans (Vicia faba); (b) field beans mechanically crushed in a two-roller mill and treated with propionic acid (trFB). (c) Field beans mechanically crushed in a two-roller mill, treated with propionic acid and extruded (exFB) at $105^{\circ} \mathrm{C} 5 \times 5 \times 6 \mathrm{~mm}$ die (EXTRU-tech E525, Sabetha, KS, USA). 
Table 1. Chemical composition of soybean meal (SBM), raw field beans treated with propionic acid $(\operatorname{trFB})$ and field beans treated with propionic acid and extruded $(\mathrm{exFB})^{1}(n=2)$.

\begin{tabular}{cccc}
\hline & SBM & trFB & exFB \\
\hline Dry Matter, \% & 88.70 & 80.75 & 87.85 \\
Gross Energy, MJ/kg & 19.22 & 18.68 & 18.45 \\
Crude Protein, \% & 53.55 & 27.37 & 27.09 \\
Lysine, \% & 2.99 & 1.78 & 1.57 \\
Threonine, \% & 1.92 & 1.05 & 0.99 \\
Methionine, \% & 0.72 & 0.22 & 0.22 \\
Cystine, \% & 0.70 & 0.30 & 0.28 \\
Tryptophan, \% & 0.77 & 0.27 & 0.25 \\
Valine, \% & 2.36 & 1.34 & 1.17 \\
Ether extract, \% & 2.47 & 1.56 & 1.58 \\
Crude Fiber, \% & 3.72 & 5.94 & 6.15 \\
Acid Detergent Fiber, \% & 5.76 & 9.28 & 9.76 \\
Neutral Detergent Fiber, \% & 8.12 & 10.15 & 10.70 \\
Ash, \% & 7.22 & 4.33 & 4.44 \\
Tannic acid equivalents, $\mathrm{mg} / \mathrm{g}$ & 0.95 & 0.79 & 0.79 \\
Trypsin Inhibitor Activity mg/g & 1.47 & 1.86 & 1.62 \\
\hline
\end{tabular}

${ }^{1}$ Units expressed on dry matter basis.

\subsection{Experiment 1}

The in-vitro ileal digestibility of dry matter (DM), organic matter (OM), and crude protein $(\mathrm{CP})$ of trFB and exFB was determined in experiment 1. A two-step in-vitro incubation procedure adapted from Boisen and Fenandez [10] and Akinsola [11] was used according to the protocol described in Torres-Pitarch et al. [12]. In short, each sample of trFB and exFB was incubated using ANKOM F-57 nylon bags in a DAISY II incubator at $39^{\circ} \mathrm{C}$ (Ankom Techn., Macedon NY, USA). The first incubation step consisted of an enzymatic hydrolysis with a pepsin solution at $\mathrm{pH} 2.0$ at $39^{\circ} \mathrm{C}$ for $5 \mathrm{~h}$. The second incubation step consisted of a hydrolysis with a multi-enzyme pancreatine (mixture of protease, amylase and lipase from porcine pancreas; Sigma-Aldrich ref. P1750, Merck KGaA, Darmstadt, Germany) at $\mathrm{pH} 6.8$ and $39^{\circ} \mathrm{C}$ for $17 \mathrm{~h}$. Each sample was incubated in duplicate, and each incubation consisted of 22 nylon bags per incubation. Laboratory analyses were performed according to the analytical methods described in Section 2.4.

\subsection{Experiment 2}

The digestible energy $(\mathrm{DE})$ and digestible $\mathrm{CP}(\mathrm{dCP})$ values of trFB and exFB were determined using the difference method [13] in experiment 2. A total of 48 male pigs [Maxgrow $\times($ Landrace $\times$ Large White); Hermitage Genetics, Sion Road, Kilkenny, Ireland] with an initial live weight of $23.3 \pm 0.66 \mathrm{~kg}$ (SEM) were housed in pairs. Pig pairs were allocated to 1 of 3 dietary treatments: (T1) Basal diet based on barley and soybean meal; (T2) $50 \%$ basal diet $+50 \%$ trFB; and (T3) $50 \%$ basal diet $+50 \%$ exFB. The ingredient composition and chemical analysis of the basal diet used in experiment 2 are presented in Table 2. Pairs of pigs were housed in fully slatted pens $(1.81 \mathrm{~m} \times 1.18 \mathrm{~m})$ with steel rail partitions. Air temperature was maintained at 20 to $22^{\circ} \mathrm{C}$. The feeders were stainless steel dry feed hoppers, $30 \mathrm{~cm}$ in width (O'Donovan Engineering, Coachford, Co. Cork, Ireland). Ad-libitum access to feed (dry pellets) and water (one drinking bowl per pen; DRIK-O-MAT, Egebjerg International A/S, Egebjerg, Denmark) was provided. Pigs were observed closely twice daily. After 7 days of adaptation to the diets, feed and fecal samples were collected over 3 consecutive days, pooled by pen and type (feed or feces), and stored at $-20{ }^{\circ} \mathrm{C}$ for later analysis (8 pens/treatment). Prior to analysis, feed and fecal samples were thawed and dried to a constant weight at $55{ }^{\circ} \mathrm{C}$ for $72 \mathrm{~h}$. After drying, samples were individually ground through a $1 \mathrm{~mm}$ screen using a CyclotecTM mill (FOSS electric, Hilleroed, Denmark). Each sample was analyzed for DM, CP, GE and acid insoluble ash (AIA) as inert marker for the determination of DE and $\mathrm{dCP}$. The DE and $\mathrm{dCP}$ was calculated 
following the equation described in Zhang and Adeola [13]. The digestibility of the test ingredient (Dti) is calculated as follows:

$$
\mathrm{Dti}=\mathrm{Dbd}+((\mathrm{Dtd}-\mathrm{Dbd}) / \mathrm{Pti})
$$

where $\mathrm{Dbd}=$ digestibility basal diet, $\mathrm{Dtb}=$ digestibility of the test diet, and Pti = proportion of the test ingredient. Laboratory analyses were performed according to the analytical methods described in Section 2.4.

Table 2. Ingredient and nutrient composition of dietary treatments of experiments 2 and 3 (in \%, on as fed basis; unless otherwise specified).

\begin{tabular}{|c|c|c|c|c|}
\hline & \multirow{2}{*}{$\begin{array}{c}\text { Experiment } 2 \\
\text { Basal Diet }\end{array}$} & \multicolumn{3}{|c|}{ Experiment $3^{1}$} \\
\hline & & $\mathrm{T} 1(\mathrm{CON})$ & T2 (trFBD) & T3 (exFBD) \\
\hline \multicolumn{5}{|l|}{ Ingredient composition } \\
\hline Barley & 76.29 & 83.02 & 54.40 & 59.60 \\
\hline $\operatorname{trFB}{ }^{2}$ & 0.00 & 0.00 & 40.00 & 0.00 \\
\hline $\operatorname{exFB}^{3}$ & 0.00 & 0.00 & 0.00 & 36.80 \\
\hline Soybean meal & 17.64 & 14.36 & 1.25 & 0.80 \\
\hline Soya oil & 3.35 & 0.00 & 1.53 & 0.03 \\
\hline Limestone flour & 1.10 & 1.12 & 1.20 & 1.15 \\
\hline Mono-dicalcium phosphate & 0.50 & 0.50 & 0.50 & 0.50 \\
\hline L-Lysine (HCl, 78.8\%) & 0.38 & 0.35 & 0.26 & 0.27 \\
\hline L-Threonine (98\%) & 0.17 & 0.14 & 0.17 & 0.17 \\
\hline DL-Metionine & 0.13 & 0.08 & 0.21 & 0.20 \\
\hline L-Tryptophan & 0.01 & 0.00 & 0.05 & 0.05 \\
\hline Salt & 0.30 & 0.30 & 0.30 & 0.30 \\
\hline Premix ${ }^{4}$ & 0.10 & 0.10 & 0.10 & 0.10 \\
\hline Celite & 0.03 & 0.03 & 0.03 & 0.03 \\
\hline \multicolumn{5}{|l|}{ Nutrient composition } \\
\hline Dry matter ${ }^{5}$ & 88.96 & 87.00 & 85.30 & 86.80 \\
\hline Crude Protein ${ }^{5}$ & 16.8 & 15.7 & 15.8 & 15.7 \\
\hline SID Lysine 6 & 0.99 & 0.89 & 0.89 & 0.89 \\
\hline Lysine $^{5}$ & 1.03 & 0.98 & 0.96 & 0.97 \\
\hline Ether extract ${ }^{5}$ & 6.0 & 3.1 & 4.5 & 3.5 \\
\hline Net energy ${ }^{6}, \mathrm{Mj} / \mathrm{kg}$ & 9.7 & 8.9 & 8.9 & 8.9 \\
\hline Gross energy $^{5}, \mathrm{Mj} / \mathrm{kg}$ & 16.6 & 16.1 & 16.3 & 16.2 \\
\hline Total $\mathrm{Ca}^{6}$ & 0.64 & 0.64 & 0.66 & 0.64 \\
\hline Digestible $\mathrm{P}^{6}$ & 0.24 & 0.24 & 0.24 & 0.25 \\
\hline Crude fibre $^{5}$ & 3.6 & 3.5 & 5.4 & 5.8 \\
\hline Acid detergent fibre 5 & 4.5 & 4.8 & 7.0 & 7.5 \\
\hline Neutral detergent fibre 5 & 9.9 & 10.4 & 10.8 & 12.0 \\
\hline $\operatorname{Ash}^{5}$ & 4.2 & 4.6 & 4.4 & 4.3 \\
\hline
\end{tabular}

${ }^{1} \mathrm{CON}=$ control diet based on barley and soybean meal, $\operatorname{trFBD}=$ diet based on barley and propionic acid-treated field beans, rwFBD = diet based on barley and propionic acid-treated and extruded field beans. ${ }^{2}$ Field beans treated with propionic acid. The inclusion rate of trFB corresponds to $32.3 \%$ in DM basis. ${ }^{3}$ Field beans treated with propionic acid and extruded. The inclusion rate of $\operatorname{trFB}$ corresponds to $32.3 \%$ in DM basis. ${ }^{4}$ Premix provided per kilogram of complete diet: $\mathrm{Cu}$ from copper sulphate, $15 \mathrm{mg}$; Fe from ferrous sulphate monohydrate, $24 \mathrm{mg}$; Mn from manganese oxide, $31 \mathrm{mg}$; $\mathrm{Zn}$ from zinc oxide, $80 \mathrm{mg}$; I from potassium iodate, $0.3 \mathrm{mg}$; Se from sodium selenite, $0.2 \mathrm{mg}$; retinyl acetate $0.7 \mathrm{mg}$; cholecalciferol, $12.5 \mu \mathrm{g}$; DL-alphatocopheryl acetate, $40 \mathrm{mg}$; vitamin $\mathrm{K}$, $4 \mathrm{mg}$; vitamin B12, $15 \mu \mathrm{g}$; riboflavin, $2 \mathrm{mg}$; nicotinic acid, $12 \mathrm{mg}$; pantothenic acid, $10 \mathrm{mg}$; vitamin B1, $2 \mathrm{mg}$; vitamin B6, 3 mg. ${ }^{5}$ Analyzed values (in \%, on an air-dry basis; unless otherwise specified). ${ }^{6}$ Calculated values (in \%, on an air-dry basis; unless otherwise specified).

\subsection{Experiment 3}

The effect of replacing SBM with trFB and exFB in grow-finisher diets on growth performance, carcass quality, apparent ileal digestibility (AiD), and total tract digestibility (ATTD) of DM, OM, GE, and CP was investigated in experiment 3. A total of 60 pigs [Maxgrow $\times($ Landrace $\times$ Large White); Hermitage Genetics, Sion Road, Kilkenny, Ireland] with an initial live weight of $46.2 \pm 0.52 \mathrm{~kg}$ (SEM) were housed in same sex pen groups 
of 2 pigs. The pens were blocked on the basis of sex (female and entire male) and initial body weight and assigned to 1 of 3 dietary treatments in a randomized block design ( $\mathrm{n}=10$ pens/treatment; 5 pens with entire male and 5 pens with females per treatment). The dietary treatments were: (T1) control diet (CON), (T2) diet with an inclusion rate of $40 \%$ of $\operatorname{trFB}(\operatorname{trFBD})$, and (T3) diet with an inclusion rate of $36.8 \%$ of exFB (exFBD). The different inclusion levels for trFB and exFB were due to the higher DM content of exFB compared to $\operatorname{trFB}(87.85 \%$ vs. $80.75 \%)$; the inclusion of $\operatorname{trFB}$ and exFB on a DM basis was $32.3 \%$ in $\mathrm{T} 2$ and $\mathrm{T} 3$, respectively. The ingredient composition and chemical analysis of the dietary treatments used in experiment 3 are presented in Table 2. Pairs of pigs were housed in fully slatted pens $(1.81 \mathrm{~m} \times 1.18 \mathrm{~m})$ with solid plastic partitions at the Teagasc Pig facilities (Moorepark, Fermoy, Co. Cork, Ireland). Air temperature was maintained at 20 to $22{ }^{\circ} \mathrm{C}$. The feeders were stainless steel dry feed hoppers, $30 \mathrm{~cm}$ in width ( $\mathrm{O}^{\prime}$ Donovan Engineering, Coachford, Co. Cork, Ireland). Ad-libitum access to feed (dry pellets) and water (one drinking bowl per pen; DRIK-O-MAT, Egebjerg International A/S, Egebjerg, Denmark) was provided.

The experiment lasted 63 days during which live weight and feed intake were recorded every 2 weeks and average daily gain (ADG), average daily feed intake (ADFI), and feed conversion ratio (FCR) were calculated. Fresh feces and feed samples from the feeder were collected on days 61 and 62 and stored at $-20^{\circ} \mathrm{C}$ for subsequent ATTD determination (6 pairs/treatment were randomly selected). At day 63 of the experimental period, pigs were transported to a commercial abattoir (Dawn Pork and Bacon, Waterford, Ireland), stunned with $\mathrm{CO}_{2}$, and killed by exsanguination. At slaughter, hot carcass weight was recorded, and back-fat thickness and muscle depth, measured at $6 \mathrm{~cm}$ from the edge of the split back at the level of the 3rd and 4th last rib, were determined using a Hennessy Grading Probe (Hennessy and Chong, Auckland, New Zealand). Lean content was estimated according to the following formula (S.I. No. 413/2001—Department of Agriculture Food and Rural Development, Republic of Ireland): Estimated lean meat content $(\%)=60.3$ $-0.847 \mathrm{x}+0.147 \mathrm{y}$ where $\mathrm{x}=$ fat depth $(\mathrm{mm}) ; \mathrm{y}=$ muscle depth $(\mathrm{mm})$. At slaughter, the intestinal tracts of 36 pigs (6 pairs/treatment) were recovered. Digesta samples were collected from the terminal ileum (up to $1.5 \mathrm{~m}$ proximal to the ileo-caecal valve) and stored at $-20{ }^{\circ} \mathrm{C}$ for later AiD determination [14]. Feed, feces, and ileal digesta samples were freeze-dried and individually ground through a 1-mm screen using the CyclotecTM mill. After milling, each sample type was pooled by pen ( $n=6$ per treatment) and analyzed for DM, ash, AIA, GE, and CP for determination of AiD and ATTD using the analytical methods described in Section 2.4 laboratory analysis.

\subsection{Laboratory Analysis}

Dry matter was determined according to the method AOAC.934.01 of the Association of Official Analytical Chemists (AOAC, 2005). The GE content was determined using an adiabatic bomb calorimeter (Parr Instruments, Moline, IL, USA). The CP content $(\mathrm{N} \times 6.25)$ was determined using the LECO FP 528 instrument (Leco Instruments UK LTD., Cheshire, UK) according to the method AOAC.990.03. The concentration of AIA was determined according to [15]. Amino acid concentration were determined using high-performance liquid chromatography [16]. Ether extract was determined according to the method described by Usher et al. [17] by extraction with perchlorethylene in a Foss Let 15,300 (A/S N. Foss Electric, Hillerod, Denmark). The trypsin inhibitor activity and tannic acid equivalents were determined using method num. S1196 and S1166 respectively by Sciantec Ltd. (Stockbridge Technology Centre Cawood, North Yorkshire, UK).

\subsection{Statistical Analysis}

All data were analyzed using the MIXED procedure of SAS ${ }^{\circledR}$ software version 9.4 (SAS Institute, Inc., Cary, NC, USA). In experiment 1, type of field beans (trFB or exFB) was 
included in the model as a fixed effect and the incubation batch was included in the model as a random effect. The model used in experiment 1 stands as follows:

$$
y=\mu+d+s+d \times s+i+e
$$

where $y$ is the variable of study, $d$ is the effect of diet, $\mathrm{s}$ is the effect of sex, $\mathrm{i}$ is the incubation batch, and e is the error term. In experiment 2 , the mean value for the determination of $\mathrm{DE}$ and $\mathrm{dCP}$ was reported and no statistical comparisons were made. In experiment 3, dietary treatment, sex, and their interaction were included in the models as fixed effects for the analysis of LW, ADG, ADFI, and FCR, carcass yield, muscle depth, backfat, and lean meat percentage. Initial LW was included as a covariate in the model for growth parameters and hot carcass weight for carcass quality parameters. Pen was regarded as the experimental unit, and block was included in the models as a random effect. The model used in experiment 3 stands as follows:

$$
y=\mu+d+s+d \times s+b+e
$$

where $y$ is the variable of study, $d$ is the effect of diet, s is the effect of sex, b is the block, and e is the error term. A compound symmetry covariance structure was fitted to all data. Model suitability was investigated by checking normality of scaled residuals using the Shapiro-Wilk test within the UNIVARIATE procedure of SAS. The results are presented as least square means \pm SEM. Differences in least square means were investigated using the $t$-test after Tukey-Kramer adjustment for multiple comparisons. Significance is reported for $p \leq 0.05$ and tendencies toward significance are reported for $p \leq 0.10$.

\section{Results}

\subsection{In-Vitro Digestiblility (Experiment 1)}

The in-vitro digestibility results of trFB and exFB are presented in Table 3 . The invitro digestibility of exFB compared to trFB was not significantly changed for DM, and significantly increased for OM and CP.

Table 3. Effect of extruding raw field beans on in-vitro digestibility of dry matter (DM), organic

\begin{tabular}{|c|c|c|c|}
\hline & Dry Mater & Organic Mater & Crude Protein \\
\hline $\operatorname{trFB}^{1}$ & 73.4 & 73.0 & 90.7 \\
\hline $\mathrm{exFB}^{2}$ & 74.4 & 74.5 & 91.0 \\
\hline Pooled SEM ${ }^{3}$ & 0.23 & 0.03 & 0.02 \\
\hline$p$-value & 0.12 & 0.02 & 0.04 \\
\hline
\end{tabular}
matter (OM), and crude protein (CP), (on a \% DM basis) $(n=4)$.

$\overline{{ }^{1} \text { Field beans treated with propionic acid. }{ }^{2} \text { Field beans treated with propionic acid and extruded. }{ }^{3} \text { Standard }}$ error of the mean.

\subsection{Digestible Energy and Crude Protein Determination (Experiment 2)}

The DE and dCP values (on DM basis) obtained for $\operatorname{trFB}$ were $14.38 \mathrm{MJ} / \mathrm{kg}$ and $21.4 \%$ (ATTD coefficient of $\mathrm{CP}=78.0 \%$ ), respectively. The DE and $\mathrm{dCP}$ values (on DM basis) obtained for exFB were $15.75 \mathrm{MJ} / \mathrm{kg}$ and 21.4\% (ATTD coefficient of CP = 79.1\%), respectively.

\subsection{Growth Performance and Carcass Quality (Experiment 3)}

The effect of replacing dietary SBM with trFB and exFB on AiD and ATTD of growfinisher pigs is presented in Table 4. Dry matter and OM AiD were higher in pigs fed exFBD than pigs fed the CON diet, but similar to pigs fed the trFBD (Table 4). Dry matter, $\mathrm{OM}$ and CP ATTD did not differ among dietary treatments (Table 4). 
Table 4. Effect of partially replacing dietary soybean meal with field beans treated with propionic acid (trFBD) and extruded (exFBD) on apparent ileal digestibility (AiD) and apparent total tract digestibility (ATTD) of grow-finisher pigs $(n=6 \text { pairs of pigs } / \text { treatment })^{1}$.

\begin{tabular}{cccccccc}
\hline & \multicolumn{3}{c}{ Treatment $^{2,3}$} \\
\cline { 2 - 8 } & CON & trFBD & exFBD & SEM $^{\mathbf{4}}$ & Diet & Sex & Diet $\times$ Sex \\
\hline AiD of DM & $65.4^{\mathrm{a}}$ & $69.9^{\mathrm{a}, \mathrm{b}}$ & $72.3^{\mathrm{b}}$ & 1.61 & 0.02 & 0.31 & 0.62 \\
AiD of OM & $68.5^{\mathrm{a}}$ & $73.2^{\mathrm{a}, \mathrm{b}}$ & $75.2^{\mathrm{b}}$ & 1.46 & 0.01 & 0.33 & 0.61 \\
AiD of CP & 63.7 & 63.3 & 63.3 & 3.20 & 0.39 & 0.66 & 0.83 \\
AiD of Energy & 66.1 & 71.0 & 71.2 & 2.18 & 0.33 & 0.44 & 0.77 \\
ATTD of DM & 88.3 & 85.9 & 88.7 & 0.29 & 0.13 & 0.26 & 0.88 \\
ATTD of OM & 89.9 & 87.9 & 90.1 & 0.27 & 0.15 & 0.31 & 0.46 \\
ATTD of CP & 85.2 & 84.0 & 86.2 & 0.57 & 0.33 & 0.34 & 0.72
\end{tabular}

${ }^{1} \mathrm{CON}=$ control diet based on barley and soybean meal; trFBD = diet based on raw field beans treated with propionic acid; exFBD = diet based on extruded field beans treated with propionic acid. ${ }^{2}$ Values are least square means. ${ }^{3, a, b}$ Values within a row that do not share a common superscript are statistically different $(p<0.05)$. ${ }^{4}$ Standard error of the mean.

The effect of replacing dietary SBM with trFB and exFB on growth performance and carcass quality traits of grow-finisher pigs is presented in Table 5 . Pigs fed trFBD and exFBD had higher ADFI than pigs fed the CON diet $(p<0.05)$. Average daily gain, FCR, carcass weight, kill out percentage, fat depth, and muscle depth did not differ among dietary treatments $(p>0.05)$. There was no statistical difference in the associated interactions between dietary treatment, sex, and week.

Table 5. Effect of partially replacing dietary soybean meal with field beans treated with propionic acid ( $\operatorname{trFB}$ ) and extruded trFB (exFB) on growth performance and carcass quality of grow finisher pigs $(n=10 \text { pairs of pigs } / \text { treatment })^{1}$.

\begin{tabular}{|c|c|c|c|c|c|c|c|}
\hline & \multicolumn{3}{|c|}{ Treatment $^{2,3}$} & \multirow[b]{2}{*}{ SEM $^{4}$} & \multicolumn{3}{|c|}{$p$-Value } \\
\hline & $\mathrm{CON}$ & trFBD & exFBD & & Diet & Sex & Diet $\times$ Sex \\
\hline $\begin{array}{l}\text { Initial live } \\
\text { weight, kg }\end{array}$ & 46.2 & 46.2 & 46.2 & 0.52 & 0.98 & 0.72 & 0.77 \\
\hline $\begin{array}{c}\text { Final live } \\
\text { weight, kg }\end{array}$ & 109.1 & 112.8 & 111.0 & 0.99 & 0.11 & 0.06 & 0.77 \\
\hline ADFI, g/day & $2291^{a}$ & $2453^{b}$ & $2403^{b}$ & 43.8 & 0.02 & 0.03 & 0.16 \\
\hline ADG, g/day & 998 & 1058 & 1027 & 22.4 & 0.13 & $<0.01$ & 0.85 \\
\hline FCR, $\mathrm{g} / \mathrm{g}$ & 2.30 & 2.32 & 2.35 & 0.027 & 0.42 & $<0.001$ & 0.15 \\
\hline $\begin{array}{l}\text { Hot carcass } \\
\text { weight, } \mathrm{kg}\end{array}$ & 84.4 & 86.9 & 85.7 & 1.13 & 0.12 & 0.21 & 0.76 \\
\hline Carcass yield, $\%$ & 77.2 & 77.3 & 77.1 & 0.37 & 0.48 & 0.12 & 0.62 \\
\hline Fat depth, mm & 11.2 & 12.8 & 12.2 & 0.56 & 0.14 & 0.15 & 0.11 \\
\hline $\begin{array}{c}\text { Muscle } \\
\text { depth, mm }\end{array}$ & 60.7 & 59.7 & 57.8 & 2.62 & 0.47 & 0.35 & 0.68 \\
\hline Lean meat, \% & 59.9 & 58.4 & 58.3 & 0.78 & 0.16 & 0.23 & 0.14 \\
\hline
\end{tabular}

${ }^{1} \mathrm{CON}=$ Control diet based on barley and soybean meal; trFBD = Diet based on raw field beans treated with propionic acid; exFBD = diet based on extruded field beans treated with propionic acid. ${ }^{2}$ Values are least square means. ${ }^{3, a, b}$ values within a row that do not share a common superscript are statistically different $(p<0.05)$. ${ }^{4}$ Standard error of the mean.

\section{Discussion}

The trFB used in this experiment had a lower DM content (80.8 vs. 88.7\%), GE (18.7 vs. $19.2 \mathrm{MJ} / \mathrm{kg})$, and CP (27.4 vs. $53.6 \%)$ than the SBM used in this experiment (Table 1). The content of crude fiber was higher in trFB than in SBM (5.9 vs. 3.7\%). Compared to the average values described in the literature for field beans grown in continental Europe [7], the trFB used in this experiment had a lower CP content (27.4 vs. $31.1 \%$ ) and similar GE (18.7 vs. $18.7 \mathrm{MJ} / \mathrm{kg}$ ). All values discussed above are expressed as DM basis. These results are in line with the chemical values reported in trials with field beans grown 
in Britain [18] where the CP value of British grown field beans is also lower than that of continental European grown field beans. The authors believe that these lower nutritional values may be related to different harvest conditions between countries, the use of varieties that are selected to have low levels of antinutritional factors, and to suit the cooler and wetter growing conditions experienced in Ireland and Britain. As expected, when trFB was extruded, the DM value and GE content of exFB were increased. The antinutritional factors analyzed [trypsin inhibitor activity (TIA) and tannin acid equivalents] for SBM, trtFB, and exFB were low and similar among trtFB, exFB, and SBM. The results obtained for TIA are in line with those obtained by [19] with a commercial, white-flowered variety of field beans. Grow-finisher pigs should not receive more than $3.0 \mathrm{TIU} / \mathrm{mg}$ in the final feed [20]. To our knowledge, maximum levels of tannins in pig diets are not described in the literature, and some recent research now consider tannin extracts as active compounds to modulate gut health in pigs rather than classifying them as antinutritional factors [21]. The tannin extracts used in monogastric nutrition are usually of seed origin (chestnuts and grapeseed) and included at between 0.05 and 5\% in the diet [18]. Dietary tannins have also been found to accumulate in bone tissue, suggesting that ingredients rich in tannins may have bone-strengthening properties [22]. However, more research on the impact of dietary tannins in monogastric nutrition is needed to determine the tannin sources and concentrations most likely to show benefit in pigs.

Field beans are harvested in Ireland with a high moisture content up to and exceeding $20 \%$. Propionic acid treatment of raw harvested field beans prior to storage is a common practice in the feed industry to allow moist storage of the field beans while preventing the proliferation of yeasts and molds during storage. This practice has also been successfully used in the storage of maize [23], wheat, and barley. Propionic acid has a disagreeable rancid odor that might be associated with lower palatability [24]. Nevertheless, studies to date, have not shown a reduction in feed intake when propionic acid was supplemented to pig diets [25]. Propionic acid has recently been considered as a feed additive to favorably modulate the gut microbiota in piglets $[24,26]$, however the dietary concentrations used in these trials are higher than in the present study. Furthermore, the benefit of organic acids like propionic acid is less well documented in grow-finishing pigs compared to weaned piglets. An alternative to propionic acid storage of field beans is to dry the seeds prior to storage, however, in practice the hardness of dried field bean seeds is such that they can be extremely damaging to feed mill equipment such as elevators and because of this moist storage is often the preferred method of storage by the feed industry for field beans.

In this experiment, extrusion of trFB increased the in-vitro digestibility of OM and CP. However, this trend was not observed in the in-vivo experiment where nutrient digestibility values remained unchanged when diets formulated with trFB and exFB were fed to growfinisher pigs. The in-vitro assay was performed on the field beans themselves while the in-vivo assay was performed on complete diets with an inclusion level of $32.3 \%$ (on a DM basis) of field beans. Therefore, this lack of consistency between the in-vitro and in-vivo results may be attributed to a dilution effect and possibly interactions of field beans with the other dietary components. To our knowledge, in-vitro digestibility of trFB or exFB has not been previously reported in the literature. In this experiment, similar ileal and total tract apparent digestibility were found in pigs fed SBM-based diets and trFB diets. This result agrees with [27] who found similar CP ATTD when replacing SBM with a 30\% inclusion of raw field beans in diets for grow-finisher pigs. Feeding exFB in diets in this experiment increased the AiD of DM and OM compared to that of pigs fed SBM-based diets. Comparable digestibility values for extruded field beans could not be found in the literature.

The in-vitro digestibility values for field beans reported in this experiment are in line with those found in the literature. Jezierny et al. [28] reported in-vitro digestibility values between 77 and $94 \%$ for different varieties of field beans. The DE values generated in this experiment for trFB and exFB (14.38 and $15.75 \mathrm{MJ} / \mathrm{kg}$, respectively) are in line with values reported in the literature [7,29]. Sauvant et al. [7] reported an average value of $16.1 \mathrm{MJ} / \mathrm{kg}$ 
and de Blas et al. [29] reported a DE value of $15.9 \mathrm{MJ} / \mathrm{kg}$ for field beans. The increase in DE due to extrusion is most likely due to an increase in the gelatinized starch content in the field beans in response to cooking, however this was not assessed in the current study. In line with our results, increased $\mathrm{DE}$ values in peas due to extrusion have previously been reported [30]. The dCP generated in this experiment for trtFB and exFB $(22.8 \%$ and $21.7 \%$ respectively) are within the range of values reported in the literature $[7,29]$. Sauvant et al. [7] and de Blas et al. [29] reported an average dCP value for field beans of $22.24 \%$ and $20.98 \%$, respectively. The reduced $\mathrm{dCP}$ value of exFB compared to trtFB reported in the current study suggests that lower processing temperatures than employed here may be advisable to minimize protein degradation during the extrusion process. The values of $\mathrm{DE}$ and $\mathrm{dCP}$ reported in the current experiment are valuable to study the effect of extrusion on field beans, nevertheless, more studies determining the Net energy (NE) and standardized ileal digestibility (SID) of amino acids are needed in order to more accurately formulate diets in an efficient and sustainable manner. In this regard, Masey O'Neill et al. [18] have reported the standardized ileal digestibility values of crude protein and amino acids of field beans for broilers but similar data are lacking for pigs.

In this study SBM was practically replaced by trFB or exFB in grow-finisher diets without impairing pig growth rate, feed efficiency, and carcass characteristics. Our results are in line with those of White et al. [28] where a 30\% inclusion of low-tannin field beans successfully replaced SBM in grow-finisher pig diets without impairing growth and/or feed efficiency. However, the field bean used in that experiment were not treated with propionic acid prior to storage. In contrast to our results, Smith et al. [19] found reduced growth rates when field beans were included at 30\% in finisher pig diets; tannin levels in that study were not reported. In previous studies [31,32] impaired growth and feed efficiency were reported when raw field beans were included at $12.5 \%$ and $7.5 \%$, respectively, in grower pig diets. Trypsin inhibitor and tannin levels of the field beans varieties used in these studies [31,32], were higher than those found for the field beans used in the current study. Furthermore, in the current study field beans were treated with propionic acid previous to storage which may have had a positive effect on the nutritional value of field beans. To our knowledge, studies where propionic acid-treated field beans were used have not previously been reported in the literature. In our view, part of the success of the replacement of SBM by treated field beans may rely on the fact that the field beans in our current study were treated with propionic acid prior to storage possibly impacting positively on the growth performance results. Further research evaluating different storage conditions will be of interest for the feed industry.

In the current study, the inclusion of field beans in grow-finisher diets increased feed intake compared to SMB-based diets. The current study demonstrates that similar nutrient digestibility, growth, feed efficiency, and carcass quality traits can be achieved using locally grown field beans as a protein source for pig diets. Replacing soybean meal with field beans in grow-finisher diets will most likely have positive environmental benefits resulting from carbon saving. In order to successfully implement wider scale use of locally grown field beans in pig diets, some challenges will need to be addressed: Further research on $\mathrm{NE}$ and SID amino acid values are required; processing conditions need to be optimized; and storage capacity for moist propionic acid-treated beans needs to be increased; and most importantly a sustainable and consistent local supply of beans must be ensured. The volatility in feed ingredient prices, especially regarding protein sources, means that there is much more interest in ingredients, such as field beans, for inclusion in pig diets than heretofore. As grow-finisher diets are formulated on a least-cost basis the relative price/value of ingredients such as field beans compared with SBM will determine how widely they are substituted in pig diets.

\section{Conclusions}

Growth rate and feed efficiency was similar for propionic acid-treated field bean-based diets to soybean meal-based diets. Similarly, propionic acid-treated field beans either raw 
or extruded did not affect carcass weight at slaughter or carcass quality. Therefore, it can be concluded that propionic acid-treated field beans are a good energy and protein source for pigs that can be used to replace soybean meal in grow-finisher pig diets. Extrusion of the propionic acid-treated field beans did not improve their nutritional value for pigs and growth rate and feed efficiency was similar to that of pigs fed raw propionic acid-treated field bean-based diet.

Author Contributions: P.G.L. conceived the study and together with J.V.O.D. and A.T.-P., designed the experiment. P.G.L. directed the study. T.R. and A.T.-P. Conducted the animal study. T.R., A.T.P., E.G.M. and P.G.L. collected feed, ileal digesta and fecal samples. A.T.-P. Performed laboratory analyses supervised by J.V.O.D., A.M.P.-V. and D.T. A.T.-P. Statistically analyzed animal growth performance and physiological data. Data were interpreted by A.T.-P. Together with G.E.G., J.V.O.D., D.T., E.G.M. and P.G.L. A.T.-P. Wrote and edited the manuscript, and G.E.G., J.V.O.D., G.E.G. and P.G.L., revised the manuscript. All authors have read and agreed to the published version of the manuscript.

Funding: Research leading to these results received funding from the Teagasc-funded project PIGZYME (project no. PDPG6671) and the European Union's Seventh Framework Programme for research, technological development and demonstration (ECO-FCE; project no. 311794).

Institutional Review Board Statement: The care and use of the animals in this study was approved by the Teagasc Animal Ethics Committee (Approval no. TAEC86/2015). The experiment was conducted in accordance with Irish legislation (SI no. 543/2012) and the EU Directive 2010/63/EU for animal experimentation.

Informed Consent Statement: Not applicable.

Data Availability Statement: The data presented in this study are available on request from the corresponding author.

Acknowledgments: We thank the technical and farm staff in the Pig Development Department at Teagasc, Moorepark, for assistance with pig management and laboratory work. We also thank personnel at the Animal Nutrition Laboratory at Lyons Research Farm, University College Dublin and the Monogastric Nutrition laboratory at IRTA Mas Bover for assistance with nutrient digestibility determinations.

Conflicts of Interest: A. Torres-Pitarch work was funded by the Teagasc Walsh Scholarship programme. The funders had no role in the design of the study; in the collection, analyses, or interpretation of data; in the writing of the manuscript, or in the decision to publish the results. The remaining co-authors have no conflicts of interest with the content of this article.

\section{References}

1. Florou-Paneri, P.; Christaki, E.; Giannenas, I.; Bonos, E.; Skoufos, I.; Tsinas, A.; Tzora, A.; Peng, J. Alternative protein sources to soybean meal in pig diets. J. Food Agric. Environ. 2014, 12, 655-660.

2. De Visser, C.; Schreuder, R.; Stoddard, F. The EU's dependence on soya bean import for the animal feed industry and potential for EU produced alternatives. Oilseeds Fats Crop. Lip. 2014, 21, D407.

3. Stein, H.H.; Benzoni, G.; Bohlke, R.A.; Peters, D.N. Assessment of the feeding value of South Dakota-grown field peas (Pisum sativum L.) for growing pigs. J. Anim. Sci. 2004, 82, 2568-2578. [CrossRef]

4. Carellos, D.D.; Lima, J.A.; Fialho, E.T.; Freitas, R.T.; Silva, H.O.; Branco, P.A.; Souza, Z.A.; Vieira, N.J. Evaluation of sunflower meal on growth and carcass traits of finishing pigs. Ciência Agrotecnologia 2005, 29, 208-215. [CrossRef]

5. Torres-Pitarch, A.; Moset, V.; Ferrer, P.; Cambra-Lopez, M.; Hernández, P.; Coma, J.; Pascual, M.; Serrano, P.; Cerisuelo, A. The inclusion of rapeseed meal in fattening pig diets, as a partial replacer of soybean meal, alters nutrient digestion, faecal composition and biochemical methane potential from faeces. Anim. Feed Sci. Technol. 2014, 198, 215-223. [CrossRef]

6. Veldkamp, T.; Bosch, G. Insects: A protein-rich feed ingredient in pig and poultry diets. Anim. Front. 2015, 5, 45-50.

7. Sauvant, D.; Perez, J.M.; Tran, G. Tables of Composition and Nutritional Value of Feed Materials; Wageningen Academic Publishers: Wageningen, The Neherlands; INRA: Paris, France, 2004; ISBN 2-7380-1158-6.

8. Pasqualone, A.; Costantini, M.; Coldea, T.E.; Summo, C. Use of Legumes in Extrusion Cooking: A Review. Foods 2020, $9,958$. [CrossRef]

9. Revilla, I. Chapter 40-Impact of Thermal Processing on Faba Bean (Vicia faba) Composition. In Processing and Impact on Active Components in Food; Preedy, V., Ed.; Academic Press: Cambridge, MA, USA, 2015; pp. 337-343. 
10. Boisen, S.; Fernández, J. Prediction of the apparent ileal digestibility of protein and amino acids in feedstuffs and feed mixtures for pigs by in-vitro analyses. Anim. Feed Sci. Technol. 1995, 51, 29-43. [CrossRef]

11. Akinsola, M.P. Development of an In-vitro Technique to Determine Digestibility of High Fiber Pig Feed. Ph.D. Thesis, Department of Animal Science, Tshwane University of Technology, Pretoria, South Africa, 2013.

12. Torres-Pitarch, A.; McCormack, U.M.; Beattie, V.E.; Magowan, E.; Gardiner, G.E.; Pérez-Vendrell, A.M.; Torrallardona, D.; O'Doherty, J.V.; Lawlor, P.G. Effect of phytase, carbohydrase, and protease addition to a wheat distillers dried grains with solubles and rapeseed based diet on in-vitro ileal digestibility, growth, and bone mineral density of grower-finisher pigs. Livest. Sci. 2018, 216, 94-99. [CrossRef]

13. Zhang, F.; Adeola, O. Techniques for evaluating digestibility of energy, amino acids, phosphorus, and calcium in feed ingredients for pigs. Anim. Nutr. 2017, 3, 344-352. [CrossRef]

14. Donkoh, A.; Moughan, P.J.; Smith, W.C. Comparison of the slaughter method and simple T-piece cannulation of the terminal ileum for determining ileal amino acid digestibility in meat and bone meal for the growing pig. Anim. Feed Sci. Technol. 1994, 49, 43-56. [CrossRef]

15. McCarthy, J.F.; Bowland, J.P.; Aherne, F.X. Influence of method upon the determination of apparent digestibility in the pig. Can. J. Anim. Sci. 1997, 57, 131-135. [CrossRef]

16. Iwaki, K.; Nimura, N.; Hiraga, Y.; Kinoshita, T.; Takeda, K.; Ogura, H. Amino acid analysis by reversed-phase high-performance liquid chromatography: Automatic pre-column derivatization with activated carbamate reagent. J. Chromatogr. 1987, 407, 273-279. [CrossRef]

17. Usher, C.; Green, C.; Smith, C. The rapid estimation of fat in various foods using the Foss-Let density apparatus. Int. J. Food Sci. Technol. 1973, 8, 429-437. [CrossRef]

18. O'Neill, H.M.; Rademacher, M.; Mueller-Harvey, I.; Stringano, E.; Kightley, S.; Wiseman, J. Standardised ileal digestibility of crude protein and amino acids of UK-grown peas and faba beans by broilers. Anim. Feed Sci. Technol. 2012, 175, 158-167. [CrossRef]

19. Smith, L.A.; Houdijk, J.G.M.; Homer, D.; Kyriazakis, I. Effects of dietary inclusion of pea and faba bean as a replacement for soybean meal on grower and finisher pig performance and carcass quality. J. Anim. Sci. 2013, 91, 3733-3741. [CrossRef]

20. Royer, E.; Alibert, L.; Serin, J.F.; Gasser, A.L.; Quinsac, A.; Labalette, F. Effects of the trypsin inhibitor concentration in pig fattening diets on performance, health and carcass parameters. In Proceedings of the 13th International Symposium Digestive Physiology of Pigs, Kliczkow, Poland, 19-21 May 2015.

21. Huang, Q.; Liu, X.; Zhao, G.; Hu, T.; Wang, Y. Potential and challenges of tannins as an alternative to in-feed antibiotics for farm animal production. Anim. Nutr. 2018, 4, 137-150.

22. Alldritt, I.; Whitham-Agut, B.; Sipin, M.; Sudholme, J.; Trentacoste, A.; Trip, J.A.; Cappai, G.M.; Ditchfield, P.; Devièse, T.; Hedges, R.E.M.; et al. Metabolomics reveals diet-derived plant polyphenols accumulate in physiological bone. Sci. Rep. $2019,9,8047$. [CrossRef]

23. Young, L.G.; Brown, R.G.; Sharp, B.A. Propionic acid preservation of corn for pigs. Can. J. Anim. Sci. 1970, 50, 711-715. [CrossRef]

24. Suiryanrayna, M.V.A.N.; Ramana, J.V. A review of the effects of dietary organic acids fed to swine. J. Anim. Sci. Biotechnol. 2015, 6, 45. [CrossRef]

25. Thacker, P.A.; Campbell, G.L.; Grootwassink, J. The effect of organic acids and enzyme supplementation on the performance of pigs fed barley-based diets. Can. J. Anim. Sci. 1992, 72, 395-402. [CrossRef]

26. Long, S.; Xu, Y.; Pan, L.; Wang, Q.; Wang, C.; Wu, J.; Wu, Y.; Han, Y.; Yun, C.; Piao, X. Mixed organic acids as antibiotic substitutes improve performance, serum immunity, intestinal morphology and microbiota for weaned piglets. Anim. Feed Sci. Technol. 2018, 235, 23-32. [CrossRef]

27. White, G.; Smith, L.; Houdijk, J.; Homer, D.; Kyriazakis, I.; Wiseman, J. Wiseman. Replacement of soya bean meal with peas and faba beans in growing/finishing pig diets: Effect on performance, carcass composition and nutrient excretion. Anim. Feed. Sci. Technol. 2015, 209, 202-210. [CrossRef]

28. Jezierny, D.; Mosenthin, R.; Sauer, N.; Eklund, M. In-vitro prediction of standardised ileal crude protein and amino acid digestibilities in grain legumes for growing pigs. Animal 2010, 4, 1987-1996. [CrossRef]

29. De Blas Beorlegui, C.; Paloma García Rebollar, G.; Mateos, G.; Gorrochategui, M.; Cegarra, E.; Méndez, J.; Santomá, G.; Pérez de Ayala, P. Tablas FEDNA de composición y valor nutritivo de alimentos para la fabricación de piensos compuestos. Fund. Española Para Desarro. Nutr. Anim. 2019, 1, 236-238.

30. O'Doherty, J.; Keady, U. The nutritive value of extruded and raw peas for growing and finishing pigs. Anim. Sci. 2000, 70, 265-274. [CrossRef]

31. O'Doherty, J.V.; McKeon, M.P. A Note on the Nutritive Value of Extruded and Raw Beans for Growing and Finishing Pigs. Ir. J. Agric. Food Res. 2001, 40, 97-104.

32. Castell, A.G. Comparison of faba beans (Vicia faba) with soybean meal or field peas (Pisum sativum) as protein supplements in barley diets for growing-finishing pigs. Canad. J. Anim. Sci. 1976, 56, 425-432. [CrossRef] 